\title{
7. The limits of agricultural growth in a fragile eco-system. Total Factor Productivity in Alentejo, 1750-1850 ${ }^{1}$
}

\author{
Helder Adegar FonseCA and Jaime REIS
}

\section{Introduction}

Recent research on pre-industrial European economies has drawn attention to a degree of economic dynamism, contradicting the Malthusian/stagnationist model which flourished in European historiography for decades (Malanima, 1995; Prak, 2001; Pamuk \& Ozmucur, 2002; van Zanden, 2005; Maddison, 2005). The key to this is whether productive efficiency could be raised in a sustainable fashion and make it possible thereby for real income per capita to grow as well. Some of this arose out of small but consistent productivity improvements in the manufacturing and service sectors of certain regions but it is in agriculture that the most relevant findings of this kind have come to light. Its importance lies in the fact that it was the sector responsible for the bulk of available resources, and probably where such gains were the hardest to achieve consistently.

The cases of Dutch and English agriculture have been especially notable in this respect (Allen, 1992, 2000; de Vries \& van der Woude, 1997). Besides this, Hoffman (1996) has also shown for France that, contrary to conventional wisdom, total factor productivity (TFP) growth was possible in the long run, even in the absence of a classic agricultural revolution. Unspectacular adjustments in the combination of inputs, modest improvements in transport, better management, increased specialisation and economies of scale, all contributed to efficiency. In all these cases, a critical condition for sustained agricultural progress was a significant degree of commercialization, large urban markets connected to a good transport network, and a class of entrepreneurially minded producers. A second important condition was natural resources that were favourable to agricultural improvement. In seventeenth and eighteenth-century France, the former were widely prevalent but the latter's distribution was much less uniform. TFP gains were strongest in the Bassin Parisien, where a wetter climate and high quality soils favoured such an evolution. In contrast, in southern France where the environment was adverse, improvement was both uncertain and on a small scale.

\footnotetext{
1 The authors are grateful for helpful comments by Patrick Svensson, Mats Olsson, the members of the COST workshop in Lund in 2008 and two anonymous referees. For essential research assistance, they wish to thank Maria de Belém Fonseca, Maria Fernando Rosado and André Oliveira da Fonseca.
} 